\title{
Impact of Demographic Variables on Non Verbal Creativity among High School Students
}

\author{
K. Janardhan Reddy ${ }^{1}$, K. Viswanath ${ }^{1}$, S. Viswanatha Reddy ${ }^{2}$
}

\section{ABSTRACT}

The objective of this research is to examine the effect of gender, locality and class of study on Non Verbal creativity among 600 high school students. Creativity Scale developed by Venkatarami Reddy was used to assess the Non verbal creativity of the students. Results revealed that there is significant impact of gender, locality of residence and class of study on Non verbal creativity among high school students. Boys are high in their non verbal creativity than girls; students hailing from urban areas are secured higher non verbal creativity scores when compared with rural students and the students studying different classes differed in their non verbal creativity. $\mathrm{X}$ class students possess high non verbal creativity than VIII and IX class students and IX class students fall in between.

Keywords: Non verbal creativity, Gender, Locality and Class of study.

Education is a powerful force in bringing about desired change in knowledge, skills, attitudes, appreciations and understanding things around us. Education plays an integral part in the overall development of the personality. Empowering of children to be active participants in a knowledge society is the main aim of education. Education helps a person to draw the best out of their mind and spirit. Education plays a vital role in the personal growth and the social development among all of us. Education which transforms a person to live a better life and more importantly in a socially well being. Education does make a remarkable effect on one's personality. It imparts us with all the power and necessities in making a noticeable mark in any of the field.

At the beginning of the $19^{\text {th }}$ century the verb “to create" was rarely used. Now a day's creativity is increasingly gaining in importance. Professionals from all fields are becoming aware of its importance and the development of creative thinking. In education, creative thinking varies from completely new ideas to new ways of considering and solving problems. It has been said that creativity is not the ability to create out of nothing, but the ability to generate new ideas by combining, changing or reapplying existing ideas. The creative process takes place in the thought. Creative thinking has two aspects: Divergent Thinking (intellectual ability to think of

\footnotetext{
${ }^{1}$ Research Scholar, Dept. of Psychology, SVU College of Sciences, Tirupati

${ }^{2}$ Assistant Professor, Dept. of Psychology, SVU College of Sciences, Tirupati

(C) 2015 I J Reddy, K Viswanath, V Reddy; licensee IJIP. This is an Open Access Research distributed under the terms of the Creative Commons Attribution License (http://creativecommons.org/licenses/by/2.0), which permits unrestricted use, distribution, and reproduction in any Medium, provided the original work is properly cited.
} 
many original, diverse and elaborate thought) and Convergent Thinking (intellectual ability to logically evaluate critique and choose the best ideas from a selection of ideas). It was initially felt that only gifted or special people could be creative. Research has proved that only certain attributes are required to be creative. A creative person requires passion and commitment; fresh way of looking at things; an understanding of people and an entrepreneurial willingness to take risk and work hard, ability to convince people that the new idea is good or better. Creativity is fostered or inhibited by certain environmental pressures. Every day, we face new changes in all aspects of life and creativity is not only a means for adapting with changes but also a stimulus for producing knowledge in different fields of study. Moreover, creativity as one of the key factors in academic achievement is required special attention.

There is no one universally agreed definition of creativity but, by considering some of the writers in the field, it may be possible to replace the notion of „knowing it when one sees it " with something more specific and perhaps more tangible. Creativity is defined as the ability to bring something with existence, creativity is distinguished by novelty, originality and it's usually inventive. Creativity was believed to be human gift, a rare quality of distinguished individuals with inborn talent. Individual who is flexible in thought and action who can produce novel ideas, express his ideas fluently and long with certain personality trails is said to be creativity. Wallach and Kogan (1965) defined as creativity lies in producing more associations and are producing more that are unique. Levin (1978) defined as creativity is the ability to discover new solutions to problem or to produce new ideas, invention or works of art. It is a special form of thinking away of viewing the world and interacting with it in a manner different from that of the general population. Wilson Guilford and Christenson (1974) stated that creative process is any process by which something new is produced like an idea or an object including a new form or arrangement of old elements. The new creation must contribute to the solution of some problems. Sternberg (1985) proposes that creativity is one type of intelligence. The creative intelligence is the ability to go beyond the given data to generate novel and interesting ideas. Thus, creativity is the higher order intelligence that helps a person to translate ideas into practical accomplishments.

Over the past few decades Indian society is influenced by Western culture, the society is fast getting modernized. But the social norms, traditions, family structure, rearing practices etc., girls especially are restricted and their activities are closely supervised not only by parents and caretakers but also by neighbors in the close communities. Their thinking is guided so as to conform to the social norms and the activities also restricted which sets limits to their creativity, unlike the case of boys. (Passi,1971; Paramesh,1973; Sinha,1975; Sansanwal and Jarial,1979; Sharma ,1984; Gupta ,1990; Flaherty,1992; Sebastian,1993; Bawa and Parvinder Kaur,1995; Suresh,1997; Shan, 2000; Yang and Ching, 2004; Sindhu, 2005; Palaniappan, 2007; Narula ,2007; Krishna and Das, 2008; Habibollah, 2009; Trivedi and Bhargava, 2010; Saima Siddiqi, 2011; Ravi Kant, 2012 and Smritikana Mitra,2013). Participation in socio cultural aspects, innovative curriculum, stimulated school environment, interaction with public, life style, facilities available, opportunities, exposure etc., fortunately will be more in urban life than rural. 
This explains the development of creative thinking between rural and urban students. (Chaudhary, 1983; Marsh, 1985; Madhav and Hirdi Pal, 1990; Asmali, 1994; Sansanwal and Deepika,1997; Karimi, 2000; Bashir and Hussain, 2012; and Atefeh Kamaei and Mokhtar Weisani, 2013). According to Torrance 1962 creativity gets hampered whenever there is stress on the child. Kelly, 1965; Passi,1971; Safaya, 1981; Misra,1986; Sumangala, 1986; Trimurthy, 1987; George,2000; Kumari,2002; The stress may be in the form of adjusting to new environment, transition from one school to another and one society to another. Up to secondary school final examination (10 ${ }^{\text {th }}$ class) students are promoted to higher classes based on their attendance. But at SSC level there is pressure on the child to achieve better academic grade points. This pressure on studies promotes achievement, naturally curbs creative thinking. The foremost concern of education today is to produce quality persons through a systematic approach i.e. through schooling; who are the real assets of the society for the $21^{\text {st }}$ century. The principle objectivity of education is to make well rounded individuals capable of living fully and richly in their culture. School life is a test of a student, undergoing a transition from dependency to independency. The child's personality continues to develop during the school years. He/she still have a chance to learn how to love and to be loved, how to tolerate frustration, how to integrate conflicting points of view, how to face reality realistically, how to express creative ideas without feeling from it to channel hostile impulses into socially approved activities. Success of school education depends upon large measures on how each young boy or girl feels about his/her school experiences and practicum experiences. It makes an immense difference whether he/she acquired attitudes, values, sense of justice and habits favorable to his/her own better intellectual, creative, social and emotional developments as a result of school experience. Social and emotional maturity is desirable in the development of intellectual and creative power an end product of formal education. Keeping the above views, the following objectives are setup for the present study.

\section{OBJECTIVES:}

1. To find out whether boys and girls differ in their non verbal creativity.

2. To find out whether children belonging to rural and urban localities differ in their non verbal creativity.

3. To examine whether students of different class of study are significantly related to non verbal creativity.

Based on the above objectives the following hypotheses are formulated for the present study:

\section{HYPOTHESES:}

1. There would be significant difference between the boys and girls on their non verbal creativity.

2. There would be significant difference between the students belonging to rural and urban localities on their non verbal creativity.

3. There would be significant difference between the students from different class of study on their non verbal creativity. 
Impact of Demographic Variables on Non Verbal Creativity among High School Students

\section{Tools}

Creativity battery test standardized by Venkatarami Reddy (1982) was used in the study. The battery of creativity tests consisted of 10 subtests. Seven of them were verbal tests (Unusual Uses, Instances, and Similarities, Common problems, Impossibilities, Consequences and Product improvement) and the remaining three were nonverbal tests. They are Pattern Meanings: Line meanings and Circles. In the present investigation nonverbal test items were taken into consideration and the analysis were separately for fluency, flexibility and originality scores.

\section{Scoring}

As there is no right or wrong responses for the creativity test items much care has to be exercised in scoring them. To enhance the objectivity of scoring the usual procedure adopted is to get the responses scored by different scorers, and to see that the inter scorer reliability is high. According to Guilford,1962, Torrance,1962 and Gage and Berliner, 1975: fluency, flexibility and originality are the primary components of divergent thinking. These factors operate in the creative thinking of adults as well as children. The responses of the subjects were scored based upon the following procedure suggested by Guilford, 1951; Torrance, 1962 and Child, 1973 and followed by various investigators.\{ like Gakhar,1974; Badrinath and Sathyanarayana,1979; Venkata Rami Reddy and Balakrishna Reddy,1984; Chadha and Ghose, 1985; Misra, 1986; Syama Trimurti, 1987; Venkata Rami Reddy and Saleena,1988; Venkata Rami Reddy and Vijayakumari, 1989 etc.\} Fluency: A fluency score was obtained by totaling the number of relevant responses given by the subject. Responses that were nonsensical or which did not answer the question was posed, were eliminated before counting them. Flexibility: A flexibility score was obtained by categorizing the responses into as many discrete classifications as suggest themselves. Evidently, the subjectivity of the scorer comes into any measure of flexibility so derived; but consensus agreement among different scorers was employed by way of making the final flexibility score more objective. Originality: Different authors used different procedures to determine the originality. In this investigation, in line with Guilford (1952) and Torrance (1962) originality was defined in terms of the statistical in frequency of a given response is only relative, each response is originality of different responses may vary depending upon the statistical infrequency of each of un commonness, each level representing approximately one fifth of the total responses.

\section{SAMPLE AND DESIGN:}

The study constituted of the population from the Students of VIII, IX and X classes belonging to high schools located in Chittoor districts in Rayalaseema region of Andhra Pradesh and the schools located in urban and rural areas were selected at random, (five schools each from rural and urban areas were selected at random from each revenue division). Five boys and five girls were selected at random, from each of the class, thus giving a total of 600 subjects for the study, equally distributed between the two sexes (boys=300 \& girls=300); two localities (rural=300 \& urban= 300) and three classes (VIII=200, IX=200 \& X=200). The data was subjected into suitable statistics; a 2X2X3 factorial design was employed. 


\section{RESULTS AND DISCUSSION}

Table-I: Mean Fluency, Flexibility and Originality Scores and SDs of Different sub groups of Subjects on Non Verbal Tests.

\begin{tabular}{|c|c|c|c|c|c|c|c|c|c|c|}
\hline \multirow{2}{*}{\multicolumn{2}{|c|}{ Category }} & \multirow{3}{*}{$\frac{N}{300}$} & \multicolumn{2}{|c|}{ Fluency } & \multicolumn{2}{|c|}{ Flexibility } & \multicolumn{2}{|c|}{ Originality } & \multicolumn{2}{|c|}{ Composite } \\
\hline & & & Mean & SD & Mean & SD & Mean & SD & Mean & SD \\
\hline \multirow{2}{*}{ Gender } & Boys & & 56.95 & 21.58 & 49.10 & 21.69 & 235.68 & 45.18 & 306.61 & 53.09 \\
\hline & Girls & 300 & 46.81 & 10.92 & 38.27 & 18.95 & 211.29 & 30.67 & 297.07 & 40.19 \\
\hline \multirow{2}{*}{ Locality } & Rural & 300 & 49.43 & 15.93 & 40.23 & 19.94 & 220.13 & 44.78 & 297.97 & 43.39 \\
\hline & Urban & 300 & 54.33 & 19.25 & 47.14 & 21.62 & 226.84 & 35.38 & 305.70 & 50.66 \\
\hline \multirow{3}{*}{$\begin{array}{l}\text { Class of } \\
\text { Study }\end{array}$} & VIII & 200 & 50.33 & 16.96 & 42.67 & 19.98 & 220.89 & 43.18 & 295.82 & 45.77 \\
\hline & IX & 200 & 50.80 & 17.47 & 43.31 & 20.99 & 223.09 & 34.32 & 302.96 & 45.89 \\
\hline & $\mathrm{X}$ & 200 & 54.51 & 18.78 & 45.08 & 22.19 & 226.48 & 43.24 & 306.74 & 49.67 \\
\hline
\end{tabular}

Table I shows the mean fluency scores and SDs of different sub groups of the subjects on the non verbal tests. It could be seen from table I that the mean scores of the boys was 56.95 while that of girls scores was 46.81 this shows that boys scored higher than girls; urban students scored better $(M=54.33)$ than rural subjects $(M=49.43)$. When the students were classified according to class of study which they belonged; it was found that the mean score of the students of VIII was the least, while students of $\mathrm{X}$ scored the highest, IX class students falling in between. The mean scores of the students of the three classes were: VIII class 50.33, IX class 50.80, and X class 54.51 respectively. The mean flexibility scores of different sub groups of the subjects on non verbal test. In the case of the fluency, for flexibility also boys scored better than girls. The mean scores of boys were 49.10 while that of girls was 38.27. In case of locality, urban students $(\mathrm{M}=47.14)$ scored better than rural students $(\mathrm{M}=40.23)$ as in the case of fluency component. The mean score of VIII, IX and X classes were 42.67, 43.31 and 45.08 respectively. This shows that VIII class students scored least while the students of $X$ class students scored the highest. An examination of the table shows that the mean score of the boys was 235.68, while that of girls was 211.29, urban locality $(M=226.84)$ scored better than rural subjects $(M=220.13)$. With regard to performance of the subjects belonging to different classes, the mean scores of the students of VIII, IX and X classes were 220.89, 223.09 and 226.48 respectively on originality. This shows that VIII class students scored least while the students of X class scored the highest and IX class students falling in between. The mean obtained by the boys on composite score (M= 306.61) was better than girls $(M=297.07)$; urban students $(M=305.70)$ performed better than rural students $(M=297.97)$ and VIII and IX class students got the similar mean value while students of the $\mathrm{X}$ students score the highest mean.

To examine whether there was any significant between the non creativity of the students belonging to different gender, localities and class of study, and to probe into the effect of the 
interaction between different variables, the scores of different sub groups of subjects analyzed using analysis of variance and the results are shown in table II.

Table-II: Consolidated Summary of ANOVA of the Fluency, Flexibility and Originality Scores.

\begin{tabular}{|l|l|l|l|l|}
\hline Variable & Fluency & Flexibility & Originality & Composite \\
\hline Gender (A) & $54.82 * *$ & $49.41 * *$ & $63.94 * *$ & $6.26 *$ \\
\hline Locality (B) & $12.81 * *$ & $20.08 * *$ & $4.85 *$ & $4.12 *$ \\
\hline Class of Study (C) & $3.73 *$ & $0.87 @$ & $1.13 @$ & $2.82 @$ \\
\hline AXB & $10.18 * *$ & $80.64 * *$ & $23.27 * *$ & $1.88 @$ \\
\hline AXC & $0.27 @$ & $0.43 @$ & $0.99 @$ & $1.72 @$ \\
\hline BXC & $0.51 @$ & $2.12 @$ & $2.78 *$ & $2.05 @$ \\
\hline AXBXC & $0.60 @$ & $0.33 @$ & $6.69 * *$ & $0.83 @$ \\
\hline
\end{tabular}

** Significant at 0.01 level * Significant at 0.05 level @ Not Significant

It could be seen from the table the $\mathrm{F}$ value for gender was 54.82, which was significant at 0.01 level. This shows that there was significant difference between the mean fluency scores of boys and girls as measured by non verbal tests. The mean scores of boys and girls presented in table I show that boys were higher than girls. The F value for locality was 12.81 , which was significant at 0.01 level, indicating a significant difference between rural and urban subjects. The mean score of the subjects belonging to urban was 54.33 while those hailing from rural localities scored 49.43. This shows urban subjects were more creative than rural children as measured by the fluency component of verbal tests. The F value of 3.73 was significant at 0.05 level. This shows that there was significant difference between the non verbal creativity of the students belonging to different class of study. The obtained mean of VIII, IX and X classes were 50.33, 50.80 and 54.51. Each group differs significantly from the others. VIII class students scored the least, while the students of X class scored somewhat highest than IX class students and the IX students falling in between VIII and X class students. The F value of 10.18 for gender and locality interaction, which was significant at 0.01 level, for gender and class of study interaction, 0.27 , the $\mathrm{F}$ value of 0.51 for locality and class of study interactions are not significant and the interaction between the three variables AXBXC (F=0.60 @) was not significant.

With regard to flexibility, the F value for gender was 49.41, which was significant at 0.01 level. This indicates that there was significant difference between boys and girls with regard to the flexibility score as measured by the non verbal tests. The $F$ value for locality $(F=20.08<0.05)$. An observation of the mean scores presented in table I reveals that urban students $(\mathrm{M}=47.14)$ 
scored better than rural students $(M=40.23)$. This shows that urban subjects were more creative than rural children as measured by the flexibility component of non verbal tests. Considering the class of study, the $\mathrm{F}$ value was 0.87 which was not significant. Indicating there is no significant difference between the flexibility scores of the subjects belonging to different classes. The $\mathrm{F}$ value of the interaction between gender and locality which was significant at 0.01 level. This shows that the gender effect on the creativity of the children was dependent the locality to which they belong. The $\mathrm{F}$ value of the interaction between sex and class of study was not significant, shows that gender effect on the non verbal creativity of the children was independent of the class to which they belong and the vice versa. The F value for the interaction between locality and class of study was not significant at any level. An examination of mean scores of the subjects classified according to two variables; shows that irrespective of their locality and sex, students of VIII class were the least score, while students of X class scored the highest mean in the group. It may be seen from the table however, that though the direction of the difference between the means was more for the both sexes. This shows that the magnitude of difference from class to class was not similar. A similar phenomenon was observed in case of fluency component also as discussed earlier. The F value (AXBXC) for three factor interaction was not significant, indicating that the effect of any two variables taken at a time was independent of the level of third variable.

The F value for gender was 63.94, significant at 0.01 level, indicating that there was significant difference between the originality of boys and girls as by the non verbal tests. This shows that there was significant difference between the mean originality scores of boys and girls as measured by non verbal tests. The mean scores of boys and girls presented in table I show that boys were higher than that of girls. With regard to variable locality the obtained $F$ value ( $F=4.85$ $<0.05$ ) is significant, table one shows urban subjects were more creative than rural children as measured by the originality component of non verbal tests. The $\mathrm{F}$ value for class of study ( $\mathrm{F}=$ 1.13>@). The means obtained by the VIII class students was somewhat less than IX class students, IX and X class students were shown significant mean difference. But the obtained means were not showing much difference. The $\mathrm{F}$ value for the gender and locality interaction ( $F=23.27>@$ ), it clearly shows there is a significant interaction between male and female on their originality, for gender and class of study $(\mathrm{F}=0.99>@)$ and locality and class of study $(\mathrm{F}=2.78>@)$, indicating that the effect of locality and class of study was not shown independently any impact on each other, when each was interacted with another one. But the obtained F value for gender, locality and class of study (AXBXC) was significant at 0.01 level. When the three variables independently interacted one variable with another was shown 
significant impact. But the three variables combined together, it shown the significant impact on originality scores.

An examination about the composite scores the $\mathrm{F}$ value for gender was 6.26, which was significant at 0.05 level. It shows that there was significant difference between the mean composite scores of boys and girls as measured by non verbal tests. The F value for locality was 4.12, which was significant at 0.01 level, indicating that there is a significant difference between rural and urban subjects. This shows urban subjects were more creative than rural children as measured by the composite component of non verbal tests. The $\mathrm{F}$ value of 2.82 was not significant, shows that there is no significant difference between the non verbal creativity of the students belonging to different class (VIII, IX \& X) of study. Then the gender and locality; gender and class of study; and gender, locality and class of study interactions, the $\mathrm{F}$ values \{AXB (F=1.88); AXC ( F=1.72); BXC (F=2.05) \& AXBXC ( $F=0.83)\}$ respectively it clearly indicates that there is no interaction between the three variables.

\section{CONCLUSIONS}

1. With regard to their fluency, flexibility, originality and composite (Non verbal creativity) scores: boys are better than girls on their non verbal creativity.

2. There is a statistical significant between rural and urban students with regard to their fluency, flexibility, originality and composite (Non verbal creativity). Urban students are better than rural student.

3. Class of study of the subjects was not shown major significant impact on non verbal creativity. X class students obtained higher score on fluency, flexibility and originality than the students studying VIII and IX classes. VIII class students i.e., (lower class of study in the group) secured low creativity scores.

\section{REFERENCES:}

Asmali, F. (1994). Relationship between Academic Achievements in Science, Scientific

Atefeh Kamaei, J. \& Mokhtar Weisani, F. (2013). Relationship between Achievement Motivation, Creativity and Academic Performance among Secondary School Students. Journal of Applied Psychology and Education, 6, (7), 21-29., 33, (1), 101-112.

Attitude and Creativity of High School Students. Asian Journal of Psychology

Badrinath, S. \& Satyanarayanan, S.B. (1979). Correlates of Creativity and Academic Achievement of Secondary School Students. Creativity Newsletter, 7, (2-1), 53-67.

Bashir,K. \& Hussain,J. (2012). A Study on Creativity and Academic Achievement of Secondary School Students. Journal of Personality and Social Psychology, 51, (3), 62-78.

Bawa, P. \& Parvinder Kaur, K. (1995). The Relationship between Creativity with their Subjects of Academic Achievement among High School Students. Journal of Psychology, 86, (2), 301-309.

Chadha, G.\& Ghose, S.D. (1985).The Gender Deference on Creativity of Secondary School Students. Social Forces, 65,650-664. 
Chaudhary, Vineeta.(1983).(Uttarakhand). Impact of academic achievement on creativity. Indian Journal of Psychometrics and Education, 39, (2), 176-177.

Flaherty, M.A. (1992). The Effects of Holistic Creativity Programs on the Self Concept and Creativity of Third Graders. The Journal of Creative Behavior, 26, (3), 165-171.

Gakhar, S.C. \& Manhas, K.D. (2006). Emotional Intelligence as correlates to Intelligence, Creativity and Academic Achievement of high school students. Unpublished Ph.D thesis, Department of Education, Punjab University, Chandigarh.

George, Tharamma T. (2000). Some Correlates of Mathematical Creativity. Unpublished Doctoral Dissertation, University of Kerala, Thiruvananthapuram.

Gupta,R. (1990). A Study on Creativity in relation to Academic Achievement among High School Students. Creativity Newsletter, 1 (1), 26-38.

Habibollah, H. (2009). The relationship between creativity and academic achievement among secondary school students. Journal of Educational Psychology, 102, (1), 180-196.

Karimi, A. (2000). The relationship between anxiety, creativity, gender, academic achievement and Social prestige among secondary school. University of Shiraz, Shiraz.

Kelly, S. (1996). The Non verbal Creativity of High School Students. Social Psychology of Education, 10, 331-352.

Krishna, T. Das, M. (2008). The relationship between Creativity and Academic Achievement of Senior Secondary School Students. Creativity Research Journal, 15, 130-138.

Kurnari, K. (1978). A Study of the Relationship among Creativity, Intelligence, Adjustment and value patterns in Adolescence. Doctoral Dissertation, Agra University. In M. B. Butch(Ed.). Fourth survey of research in education. New Delhi: NCERT.

Madhav, K.\& Hirdi Pal, O. (1990). The Relationship between Gender, Locality and Creativity on Academic Achievement of Secondary School Students. Journal of Psychology, 84,(1), 135-142.

Marsh, M. (1985). A study on Creativity and Academic Achievement of High School Students. Journal of Psychological Researches, 39, (1), 51-55.

Misra, K. S. (1 986). Effect of School and Home Environment on Scientific Creativity. Unpublished M.Ed. Dissertation Department of Education, Sangyanalaya. Kanpur.

Misra, T.H. (1986). Effect of Home and School Environments on Scientific Creativity among High School Students. Journal of Developmental Psychology, 1, 32-37.

Narula, N. (2007). A study of academic achievement in mathematics in relations to emotional intelligence, creativity learning styles and mathematical aptitude at high school stage. Ph.D. (Edu.) Thesis, Punjab University Chandigarh.

New Encyclopedia Britannica. (2002). Encyclopedia Britannica, Inc., Chicago London.

Palaniappan, A. K. (2009). Influence of Intelligence on the Relationship between Creativity and Academic Achievement. Unpublished Doctoral thesis, Department of Educational Psychology and Counseling, University of Malaya, Kuala Lumpur, Wilayah Persekutuan, Malaysia.

Parmesh, C. R. (1973). Relationship between Academic Achievement and Creative Thinking. The Educational Trends, 8, (1-3), 138-147. 
Passi, K. (1971). The Nonverbal Creativity of Secondary School Students. Psychological Reports, 29 (7), 34-45.

Passi, K. (1971). The Nonverbal Creativity of Secondary School Students. Psychological Reports, 29 (7), 34-45.

Ravi Kant, (2012). A Study of Creativity of Secondary School Children as a Correlate of Some Television Viewing Habits. International Journal of Modern Education and Computer Science, 10, 33-39.

Runco, M. A. (2007). Achievement Sometimes Requires Creativity. High Ability Studies. 18 (1), 75-77.

Safaya, M. (1981). The Intelligence and Creativity as Predictors of Over-Under Achievement in different School Subjects. Department of Education, Unpublished M.Ed. Dissertation, Panjab University, Chandigarh.

Saima Siddiqi (2011). A comparative study of creativity among high school students. Indian Educational Review, 49, (2), 1-9.

Sansanwal Deepika, M.G. (1997). The Creativity and Gender differences among High School Students. , Journal of Educational Research, 35, (3), 167-173.

Sansanwal, D.N. \& Jarial, G.S. (1979). Creativity in relation to their Subjects of High School Students. Journal of Institution of Educational Research, 3, 24-35.

Sebastian, H.C. (1993). The Effect of Gender and Creativity among Secondary School Students. Monographs of the Society for Research in Child Development, 55, (1-2), 22.

Shan, H.R. (2000). Identification and Development of Creativity. Ajay Verma Common Wealth Publishers, New Delhi.

Sharma, K. (1984). A Comparative Study on Creativity and Academic Achievement among High School Students. Ph.D. Thesis, Jamia Millie Islamia University, New Delhi.

Sindhu, G. (2005). Relationship among Creativity, Classroom Adjustment and Academic Achievement of Students at Higher Secondary Level. Unpublished M. Phil. Thesis, School of Pedagogical Sciences, Mahatma Gandhi University. Kottayam, Kerala.

Sinha, N.C.P. (1975). The relationship between Creativity and Academic Achievement among High School Students. Indian Psychological Review, 16, (2), 164-176.

Smritikana Mitra Ghosh. (2013). Gender differences in creativity among high school students. Indian Journal of Applied Research, 3, (7), 583-584.

Sternberg, R.J. (1985). Cognitive processes in problem solving. New York: Longman.

Sumangala, V. (1986). Some Psychological and Social Familial correlates of Creative Behavior among Secondary School Children. Department of Education, Unpublished Ph.D. Thesis, Kerala University, Thiruvananthapuram.

Suresh, B. (1997). A Study on Creativity and Academic Achievement in Biology Subject of High School Students. Journal of Personality Assessment, 36, (4), 51-59.

Syama Thrimurthy, G.D. (1987). A Study on Study Habits, Intelligence and Creativity of Higher Secondary School Students. Journal of Experimental research on Education, 37, 13-16. 
Torrance, E. P. (1965). Rationale of the Torrance Tests of Creative Thinking Ability. In Torrance, E. P. and W. F. White (Eds). Issues and Advances in Education Psychology, 24, (6), 168-175.

Torrance, E.P. (1963). Education and the Creative Potential. Minneapolis, MN: University of Minnesota Press.

Trimurthy, L. (1987). A Study on Creativity and Intelligence of High School Students. Indian Educational Review, 24 (3), 116-124.

Trivedi, K. \& Bhargava, R. (2010). Relation of creativity and educational achievement in adolescence. Journal of Psychology, 1, (2), 85-89.

Venkata Rami Reddy, A. and Saleena,K (1988). Creativity Vs Age. Perspectives in Education, 4, 245-250.

Venkatarami Reddy, A. \& Balakrishna Reddy, P. (1984). Creativity of Adolescent Boys and Girls in relation to Some Variables. Indian Educational Review, 19, 1 .

Yang, S. \& Ching, L. (2004).The Relationship between Creative Thinking Styles in Taiwan Secondary School Students. Journal of Instructional Psychology, 31(1), 33-45. 